УДК 575.222.73:575.1

(C) Н.Д. Тихенко ${ }^{1}$,

Н.В. Цветкова ${ }^{2}$,

А.Н. Лыхолай ${ }^{2}$,

А. В. Войлоков ${ }^{1}$

${ }^{1}$ Санкт-Петербургский филиал Института общей генетики им. Н. И. Вавилова РАН; ${ }^{2}$ ФГБУ ВПО «Санкт-Петербургский государственный университет»

У культурных растений известны гены, ведущие к гибели или стерильности отдалённых гибридов. В статье обобщены собственные данные по генетике гибридной летальности, которая была обнаружена в скрещиваниях мягкой пшеницы с инбредными линиями ржи. Показано, что гибридная летальность является следствием негативного взаимодействия комплементарных генов пшеницы и ржи. Однако эмбриональная летальность, свойственная отдельным пшенично-ржаным гибридам, не может быть отнесена к эволюционно сложившейся межродовой несовместимости, которую представляет хорошо изученная презиготическая несовместимость мягкой пшеницы и родственных ей родов.

\section{\%лючевые слова:}

комплементарные гены гибридной летальности; пшенично-ржаные гибриды; инбредные линии ржи; постзиготическая репродуктивная изоляция; картирование генов.

Поступила в редакцию 25.05.2015 Принята к публикации 08.09.2015

\section{ИДЕНТИФИКАЦИЯ КОМПЛЕМЕНТАРНЫХ ГЕНОВ ГИБРИДНОЙ ЛЕТАЛЬНОСТИ В СКРЕЩИВАНИЯХ МЯГКОЙ ПШЕНИЦЫ С РОЖЬЮ. ИТОГИ И ПЕРСПЕКТИВЫ ИССЛЕДОВАНИЙ}

\section{ВВЕДЕНИЕ}

Межродовые скрещивания гексаплоидной пшеницы с сортами и линиями ржи дают, как правило, всхожие гибридные зерновки (Ригин, Орлова, 1977). Использование для скрещивания с пшеницей Chinese spring (CS) свыше ста инбредных линий ржи Петергофской генетической коллекции позволило обнаружить линии, при гибридизации которых с пшеницей CS образуются зерновки с мёртвыми зародышами (Voylokov, Tikhenko, 2002). Установленная летальность пшенично-ржаных гибридов соответствует межвидовой постзиготической несовместимости, проявляющейся в гетероплидных и гомоплоидных скрещиваниях и основанной на разных генетических механизмах (Войлоков, Тихенко, 2009; Rieseberg, Blackman, 2010). Одним из таких механизмов является комплементарное негативное взаимодействие доминантных генов, принадлежащих родительским видам. Эволюция постзиготической межвидовой изоляции длительное время была неразрешенным вопросом (Orr, 1996), поскольку появлению нежизнеспособных или стерильных гибридов на внутрипопуляционном уровне не может благоприятствовать естественный отбор. Однако если постзиготическая изоляция вызвана взаимодействием несовместимых мутаций (аллелей), принадлежащих разным генам и фиксированным в аллопатрических популяциях, тогда отбор не будет препятствовать её эволюции (Dobzhansky, 1937; Muller, 1942). В этом случае возникшие мутации являются нейтральными или благоприятными на собственном генотипическом фоне, но проявляются как несовместимые при гибридизации с другой популяцией. Обнаружение межлинейной изменчивости по проявлению гибридной эмбриональной летальности позволило нам провести серию исследований, направленных на проверку этой гипотезы в отношении пшенично-ржаных гибридов. В статье описываются разработанные подходы к генетическому изучению межродовой гибридной летальности, полученные на их основе результаты, а также приводится обсуждение этих результатов в связи с известными механизмами репродуктивной изоляции, разделяющими рожь и пшеницу.

\section{ПРОВЕДЕНИЕ СЕГРЕГАЦИОННОГО АНАЛИЗА ЭМБРИОНАЛЬНОЙ ЛЕТАЛЬНОСТИ}

Нежизнеспособные семена были обнаружены в скрещиваниях CS c четырьмя линиями ржи, три из которых являются родственными. Изучение срезов набухших семян показало, что морфологически оформленный зародыш у зерновок отсутствует или представлен мертвыми клетками (Тихенко и др. 2005). Нежизнеспособность зародышей была подтверждена с помощью тетразольно-топографического метода (метод определения жизнеспособности, ГОСТ 12039-82). Метод основан на способности дегидрогеназ живых клеток зародыша восстанавливать бесцветный раствор хлористого тетразола в формазан. В результате жизнеспособный зародыш приобретает красный цвет, а мертвый остается неокрашенным.

Согласно предложенной схеме гибридологического анализа (Voylokov, Tikhenko, 2002), линию 2 (л.2), дающую нежизнеспособные семена в скрещиваниях с пшеницей, скрещивали с линиями 6 и 7 (л.6 и л.7), дающими нор- 
мальные жизнеспособные семена. Затем пыльцу межлинейных гибридов $\mathrm{F}_{1}($ л. $2 \times$ л.6) и $($ л. $2 \times$ л. 7$)$ использовали для опыления кастрированных колосьев двух сортов мягкой пшеницы, несущих гены скрещиваемости с рожью. Полученные семена замачивали, и зародыши окрашивали с помощью хлористого трифенилтетразолия $\left(\mathrm{C}_{19} \mathrm{H}_{15} \mathrm{~N}_{4} \mathrm{Cl}\right)$, после чего подсчитывали соотношение семян с жизнеспособными и нежизнеспособными зародышами. В обеих комбинациях скрещивания это соотношение соответствовало $1: 1-$ соотношению, ожидаемому для гаметического расщепления по одному гену ржи, представленному у межлинейного гибрида двумя аллелями. Обнаруженный ген получил обозначение Eml (Embryo lethality), заглавная буква в этом символе соответствует условно мутантной аллели, строчное написание $e m l$ обозначает аллель дикого типа, свойственную большинству изученных линий ржи. Идентичное расщепление было получено и при анализе гибридов с линией 535 (л.535), неродственной линии 2 (Тихенко и др., 2005). Вопрос об аллелизме мутаций эмбриональной летальности мог быть решен только при сегрегационном тесте на аллелизм, так как проведение функционального теста требует сочетания обеих мутаций в гетерозиготе, что в нашем случае не представляется возможным. Кроме того, сегрегационный тест на аллелизм универсален для доминантных и рецессивных мутаций, одинаково проявляющихся на гаплоидном уровне. Для проведения такого теста пыльцу межлинейного гибрида $\mathrm{F}_{1}$ (л.2× л.535) использовали для опыления кастрированных цветков пшеницы CS. Все зерновки из 1878 проанализированных (Тихенко и др., 2005) оказались невсхожими, что может говорить об аллелизме мутаций эмбриональной летальности, свойственных этим линиям. Альтернативой аллелизму является предположение о тесном сцеплении двух разных генов, мутации в каждом из которых ведут к гибели гибридных семян. Сделать выбор между этими гипотезами на основании сегрегационного теста на аллелизм практически невозможно, поскольку появление рекомбинантов (всхожих семян) является редким событием, как в случае внутригенной так и межгенной рекомбинации тесно сцепленных генов. Для обнаружения и анализа рекомбинантных генотипов потребуется провести анализ не двух, а десятков тысяч гибридных семян. Ключом к решению этого и ряда других вопросов должно было стать генетическое картирование гена эмбриональной летальности.

\section{УСТАНОВЛЕНИЕ ХРОМОСОМНОЙ ЛОКАЛИЗАЦИИ ГЕНА ЕМL}

В настоящее время установление хромосомной локализации генов и их генетическое картирование проводятся одновременно путем анализа совместного наследования анализируемого гена и молекулярных маркеров, плотно расположенных в геноме анализируемого вида. Гибель зародыша на ранних стадиях развития не позво- ляла провести оценку фенотипа и изоляцию ДНК для последующего фрагментного анализа непосредственно у гибридных зерновок, полученных от скрещивания $\mathrm{CS} \times \mathrm{F}_{1}$ (л. $2 \times$ л.7). Поэтому для локализации и картирования гена $E m l$ в геноме ржи использовали поколения $\mathrm{F}_{2}$ и $\mathrm{F}_{5}$ межлинейного гибрида (л. $2 \times$ л.7), который служит основой для создания рекомбинантных инбредных линий (РИЛ). На первом этапе этой работы были использованы данные по генотипированию с помощью молекулярных маркеров растений $\mathrm{F}_{2}$ (л.2× л.7) (Khlestkina et al 2004). Генотип по гену $E m l$ устанавливали при анализе зерновок, полученных от скрещивания с пшеницей растений $\mathrm{F}_{5}$ (л. $2 \times$ л.7) (Тихенко и др., 2005). С этой целью по одному растению в каждом инбредном потомстве $\mathrm{F}_{5}$ скрещивали с пшеницей $\mathrm{CS}$ и проводили посемейный учет жизнеспособности семян пшенично-ржаных гибридов. На основании этого анализа семьи пшенично-ржаных гибридов были разбиты на две группы. Первую группу составили семьи, в которых зерновки с жизнеспособными зародышами отсутствовали, соответственно генотип ржаного родителя должен быть Eml/Eml. Во вторую группу вошли семьи, в которых зерновки с жизнеспособными зародышами встречались с частотой, варьирующей от 25 до 100 \%. Разделить эти семьи, как потомства растений ржи гомо - или гетерозиготных по аллели eml, можно только с некоторой ошибкой, ориентируясь на 50 \% жизнеспособных зерновок, как на характеристику гетерозигот Eml/eml. Поэтому при оценке расщепления вторая группа семей рассматривалась нами вцелом. При таком способе анализа соотношение двух групп семей 33 : 42 соответствовало теоретическому соотношению, ожидаемому для моногибридного расщепления в $\mathrm{F}_{5}$, а именно 15Eml/Eml: $17 \mathrm{eml} /-(2 \mathrm{eml} / \mathrm{Eml}+15 \mathrm{eml} / \mathrm{eml})$. Последнее соотношение выводится на основании формулы расщепления в последовательных поколениях $\left(2^{\mathrm{k}-1}-1\right): 2:\left(2^{\mathrm{k}-1}-1\right)$, где $\mathrm{k}$ - число поколений.

Для установления сцепления в двух выделенных классах растений $\mathrm{F}_{5}$ рассматривали расщепление по кодоминантным маркерам в $\mathrm{F}_{2}$, исходя из прямого родства растений $\mathrm{F}_{2}$ и $\mathrm{F}_{5}$. Очевидно, что в случае отсутствия сцепления между кодоминантным маркером и мутацией расщепление в обоих классах должно соответствовать моногибридному соотношению $1: 2: 1$, свойственному гибридам $\mathrm{F}_{2}$ в целом. В случае сцепления маркера и мутации соотношение генотипов по маркеру среди растений $\mathrm{F}_{2}$, родоначальников выделенных групп, в $\mathrm{F}_{5}$ будет асимметричным, что легко установить с помощью критерия $\chi^{2}$. С целью локализации мутации $E m l$ в геноме ржи вышеописанный анализ провели для 54 молекулярных маркеров, картированных во всех хромосомах ржи (Войлоков, 2008). Данные, говорящие о сцеплении этой мутации с маркерами, были получены для хромосомы 6R. Для двух косегрегирующих маркеров Xgwm 1103 и Xgwm732, принадлежащих этой хромосоме, соотношение генотипов в выделенных группах оказалось асимметричным. Среди 


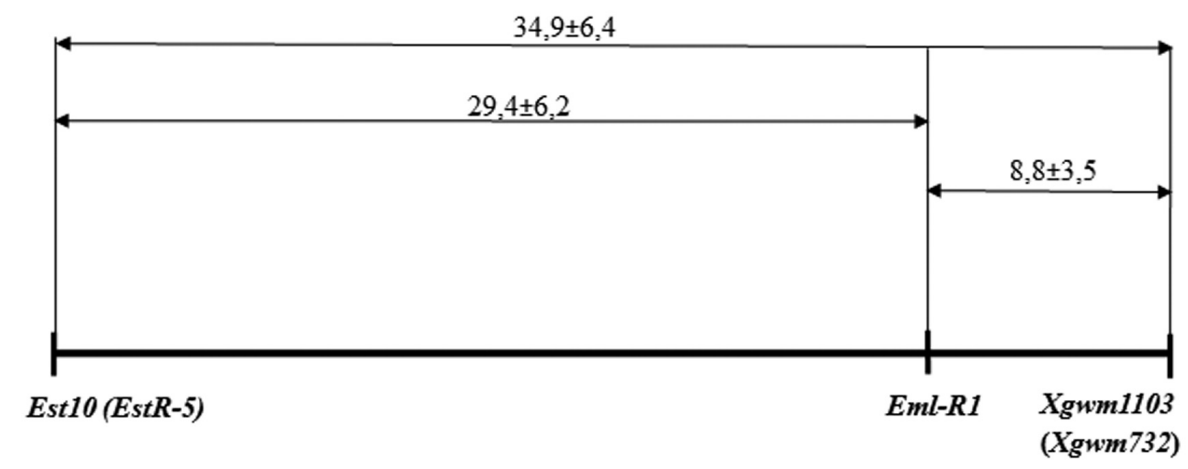

Рис. 1. Фрагмент генетической карты хромосомы 6R ржи, включающий маркеры и ген эмбриональной летальности. Частота рекомбинации указана в процентах

предков гомозигот $E m l / E m l$ в $\mathrm{F}_{2}$ преобладали гомозиготы по аллели маркера, свойственной линии 2, по сравнению с гомозиготами от линии 7. Напротив, среди предков класса, обьединяющего гомо- и гетерозиготы по аллели $\mathrm{eml}$, значительно чаще в $\mathrm{F}_{2}$ встречались гомозиготы по аллели маркера от линии 7 , чем от линии 2 . В то же время для маркеров, далеко отстоящих на генетической карте от локусов Xgwm1103/Xgwm732, расщепление в выделенных группах однородны и соответствуют соотношению $1: 2: 1$.

\section{КАРТИРОВАНИЕ ГЕНА ЭМБРИОНАЛЬНОЙ ЛЕТАЛЬНОСТИ}

Установление хромосомной локализации позволило картировать ген эмбриональной летальности с использованием маркеров, учтенных непосредственно у растений $\mathrm{F}_{5}$. С этой целью растения, участвовавшие в скрещиваниях с пшеницей, были генотипированы по двум косегрегирующим микросателлитным Xgrm 1 103/Xgwm732, и одному изозимному локусу Est 10 (EstR-5), контролирующему эстеразы листьев $(E s t 10)$ и эндосперма (EstR-5). Сложный изозимный локус Est 10 (EstR-5) был ранее картирован в положении, указывающем на его возможное сцепление с геном эмбриональной летальности (Войлоков, 2008). Прямое картирование подтвердило это предположение и позволило построить фрагмент генетической карты хромосомы 6R, включающий ген эмбриональной летальности и фланкирующие его маркеры (рис. 1). Қак и ожидалось, наиболее близко $(\mathrm{rf}=8,8 \% \pm 3,5)$ к гену расположены косегрегирующие маркеры Xgwm 1 103/Xgwm732 (Tikhenko at al., $2011)$. На расстоянии втрое большем $(\mathrm{rf}=29,4 \pm 6,2 \%)$ находятся локусы Est 10 (EstR-5).

\section{АНАЛИЗ ПРОЯВЛЕНИЯ ГЕНА ЕМL В ГЕТЕРОЗИГОТНОМ СОСТОЯНИИ}

Знание о хромосомной локализации гена $E m l$ позволило изучить его эффект в гетерозиготном состоянии, то есть установить доминантность или рецессивность несовместимой аллели в отношении проявления эмбриональной летальности (Тихенко, 2011). Для этого были получены гибриды между пшеницей CS, дополненной двумя гомологами хромосомы 6R сорта Imperial, и линией 2. Исходная пшенично-ржаная дополненная линия не имеет аномалий в развитии семян и поэтому должна нести совместимую аллель гена эмбриональной летальности. Таким образом, у зерновок, полученных в скрещиваниях 6R дополненной линий CS и линии 2 , ген $E m l$ находился в гетерозиготном состоянии. Тест на всхожесть показал, что гибридные зерновки нежизнеспособны и, следовательно, аллель несовместимости проявляет доминирование по отношению к аллели совместимости (Tikhenko et al., 2010).

\section{ИДЕНТИФИКАЦИЯ ГЕНА ПШЕНИЦЫ, КОМПЛЕМЕНТАРНОГО ГЕНУ ЕМL РЖИ В ПРОЯВЛЕНИИ ЭМБРИОНАЛЬНОЙ ЛЕТАЛЬНОСТИ}

Исходя из гипотезы о негативном взаимодействии двух генов пшеницы и ржи, как причине летальности, был предпринят поиск хромосомы пшеницы, несущей ген, комплементарный гену Eml ржи (Тихенко, 2011). С этой целью проводили скрещивание набора нулли-тетрасомных линий пшеницы CS с линией 2. Проведенный анализ мог принести успех, если ген несовместимости локализован в паре гомологичных хромосом, принадлежащих только одному из трех гомеологичных геномов гексаплоидной пшеницы (AABBDD). Тогда у двух нулли-тетрасомных линий, у которых одна и та же пара хромосом одного генома замещена гомеологичными хромосомами двух других геномов, должны формироваться всхожие зерновки при их скрещивании с линией 2. Такие зерновки были обнаружены у двух линий с отсутствием хромосомы 6A - N6A/T6B (нулли 6A тетра 6B) и N6A/T6D (нулли 6A тетра 6D) (Tikhenko et al., 2010). В дистальном участке длинного плеча хромосомы 6A картированы микросателлитные маркеры Xgwm1103/Xgwm732 
(Kosellek C. et al., 2013), которые у пшеницы так же как и у ржи наследуются сцепленно, и помимо хромосомы 6А локализованы в гомеологичном фрагменте хромосом 6D (Ganal, Roder, 2007). Важно отметить, что названные маркеры были разработаны на основе уникальных последовательностей генома пшеницы, а их способность к амплификации последовательностей, как пшеницы так и ржи говорит о высокой степени сходства (консервативности) этих последовательностей в хромосомах 6R, 6A и $6 \mathrm{D}$.

\section{ВОЗМОЖНАЯ РОЛЬ КОМПЛЕМЕНТАРНЫХ ГЕНОВ ГИБРИДНОЙ ЭМБРИОНАЛЬНОЙ ЛЕТАЛЬНОСТИ В КАЧЕСТВЕ ГЕНОВ МЕЖРОДОВОЙ ИЗОЛЯЦИИ}

Обнаружение внутривидовой изменчивости ржи по летальности пшенично-ржаных гибридов, позволило идентифицировать и картировать ген ржи, доминантная аллель которого на генотипическом фоне CS вызывает гибель зародышей. Генотипический фон, на котором проявляется несовместимый аллель ржи, удалось сузить до хромосомы 6А. Наиболее простым объяснением этого взаимодействия является предположение о наличии в этой хромосоме комплементарного гена пшеницы, который может являться несовместимым гомеологом гена $E m l$ ржи. Гомеологи этого гена в хромосомах 6В и 6D должны быть представлены активными совместимыми аллелями или инактивированы путем элиминации, мутаций или репрессии. В таком случае негативное эпистатическое взаимодействие осуществляется только между несовместимыми гомеоаллелями ржи и пшеницы, локализованными в синтенных фрагментах хромосом 6A и 6R. Однако гомеологию генов эмбриональной летальности ржи и пшеницы еще предстоит доказать. Дело в том, ген $E m l$ фланкирован маркерами, которые гомеологичны маркерам пшеницы, но локализованы в ее разных хромосомах. Косегрегирующие микросателлитные маркеры Xgwm1103 (Xgwm732) у пшеницы локализованы в хромосомах 6A (Kosellek et al., 2013) и 6D (Ganal, Roder, 2007), а ортологи локусов Est10 (EstR-5) в хромосомах третьей гомеологичной группы пшеницы (Devos et al., 1993).

Таким образом, ген $E m l$ ржи может иметь ортологов в хромосомах шестой или в хромосомах третьей гомеологичных групп пшеницы. Мозаичность длинного плеча хромосомы 6R является хорошо установленным фактом, вытекающим из двух предполагаемых эволюционных транслокаций (Devos et al., 1993; Martis et al., 2013). Показано, что длинное плечо этой хромосомы, помимо участков хромосом шестой и третьей гомеологичных групп, включает и дистальный фрагмент хромосомы седьмой гомеологичной группы.

Согласно современным представлениям, геном культурной ржи формировался в ходе эволюции за счет интрогрессивной гибридизации предковых видов и возможной аллополиплоидизации, с последующей реорганизацией генома на основании хромосомных перестроек и восстановлением диплоидного числа хромосом равного семи (Martis et al., 2013). Об этом говорят мозаичный (блоковый) состав хромосом ржи, разное эволюционное происхождение консервативных синтенных блоков, составляющих хромосомы ржи и в два раза большее количество ДНК на гаплоидный геном по сравнению с ячменем и пшеницей.

Очевидно, что периодической гибридизации предковых видов ржи могла способствовать аллогамия. Роль репродуктивной изоляции в эволюции культурной ржи не обсуждается. Также не обсуждается значение многочисленных генов постзиготической несовместимости, выявленных во внутривидовых и межвидовых скрещиваниях пшеницы разной плоидности (Войлоков, Тихенко, 2009), для эволюции мягкой пшеницы и ее предковых видов.

На уровне межродовой гибридизации несовместимость пшеницы и ржи изучена хорошо, чему в свое время способствовали исследования, направленные на создание тритикале. Исследования по гибридизации разных видов пшеницы и ржи проводили преимущественно с использованием ржи в качестве отцовской формы. Установлено, что роды Triticum и Secale разделяют, по крайней мере, четыре барьера репродуктивной изоляции, действующие до и после оплодотворения (Marais, Pienaar, 1977). Это барьеры презиготической изоляции, связанные с преимущественным самоопылением пшеницы, а также с действием доминантных генов нескрещиваемости, прерывающих рост пыльцевых трубок ржи в тканях завязи пшеницы в случае попадания пыльцы ржи на рыльце пшеницы (Lange, Wojciechowska, 1976). Постзиготическая репродуктивная изоляция обнаружена при скрещивании с диплоидными и тетраплоидными видами пшеницы. Она заключается в нарушениях развития эндосперма и связанной с этим гибелью зародыша. Развитие гибридных зародышей можно продолжить путем их ранней изоляции и культивирования на питательной среде. Эндосперм у гибридов с гексаплоидной пшеницей развивается нормально, гибридные зерновки характеризует высокая всхожесть. В качестве репродуктивного барьера выступает стерильность межродовых гибридов, которая в случае тетра- и гексаплоидных пшениц объясняется нарушениями в мейозе и может быть преодолена путем удвоения хромосом.

Действие механизмов межродовой несовместимости не абсолютно, среди видов пшеницы разной плоидности обнаружена изменчивость, проявляющаяся количественно в виде различий по проценту завязавшихся семян (Halloran, 1981), их всхожести, а также мейотической реституции у амфигаплоидов (Balatero, Darvey, 1993). В последнем случае функциональные нередуцированные гаметы образуются вследствие расхождения сестринских хроматид в первом мейотическом делении. В отношении 
перечисленных механизмов несовместимости обнаружена и внутривидовая изменчивость. В основном это касается твердой (Pilch, 2001) и мягкой пшениц и культурной ржи (Scoles, 1983; Pilch, 2001), что, очевидно, связано с интенсивными исследованиями по селекции тритикале.

Общность центра происхождения и длительное сосуществование видов культурной пшеницы и ржи в смешанных посевах, а также полей пшеницы в окружении дикорастущй ржи на ранних этапах одомашнивания, могли способствовать взаимной интрогрессии (Riley, Chapman, 1967). Однако прямые данные на геномном уровне, подтверждающие это предположение, отсутствуют. Несмотря на установленную изменчивость механизмов несовместимости, данные по генетическому контролю несовместимости существуют только в отношении нескрещиваемости пшеницы и ржи. И в этом случае они не носят исчерпывающего характера. Долгое время считалось, что за нескрещиваемость гексаплоидной пшеницы с рожью и многими другими родами злаков (Thomas et al., 1980) отвечают два доминантных гена $K r 1$ и $K r 2$. Эти гены были установлены при сегрегационном анализе нескрещиваемости (Lein, 1943), а затем локализованы цитогенетически в хромосомах 5В и 5А соответственно, (Riley, Chapman, 1967). Позднее в хромосоме 5D был локализован ген $K r 3$, предполагаемый гомеолог генов Kr1 u Kr2 (Sitch et al., 1985), а затем в хромосоме 1А найден и четвертый ген Kr4 (Zheng et al., 1992). Для каждого из установленных генов предполагается существование серии аллелей разной силы. Рецессивные мутации в этих генах нарушают функционирование системы межродовой нескрещиваемости и позволяют получить межродовые гибриды. Рецессивные аллели свойственны гексаплоидным пшеницам из центров азиатского разнообразия, в которых отсутствует дикорастущая рожь, и длительное время не возделывалась рожь посевная. Без экспериментального подтверждения считалось, что у диплоидной пшеницы с геномом А и тетраплоидной пшеницы с геномами АВ действуют гомологи генов $K r 1$ и $K r 2$, локализованные в тех же геномах, что и у гексаплоидной пшеницы с геномами ABD (Halloran, 1981). Экспериментально было показано, что у тетраплоидной пшеницы T. turgidum L. китайского сорта Ailanmai peцессивные аллели скрещиваемости локализованы в хромосомах 1A, 6А и 7A (Deng-Cai et al., 1999), в то время как высокую скрещиваемость гексаплоидной пшеницы CS связывают с тремя мутантными генами в хромосомах пятой гомеологичной группы. Все четыре мутантных гена несет ряд местных китайских сортов (Zheng et al.,1992). Таким образом, только хромосому 1 А можно рассматривать как носитель гена нескрещиваемости, свойственного как тетраплоидной, так и гексаплоидной пшенице.

Еще более осложняет представление об эволюции генов межродовой несовместимости идентификация еще одного гена нескрещиваемости $S K r$. Этот ген обнаружен при проведении маркерного анализа скрещиваемости у гибридов между сортами мягкой пшеницы с низкой скрещиваемостью и CS (Alfares et al., 2009). Он был локализован, как и ген $K r 1$, в хромосоме 5В, но не в длинном, а в коротком плече этой хромосомы. Таким образом, при установлении хромосомной локализации (Riley, Chapman, 1967) эффект двух генов (Kr1 и $S K r)$ за счет сцепления мог быть отнесен к одному гену. Эффект каждого из генов по отдельности регистрируют при использовании в генетическом анализе линий с телоцентрическими хромосомами 5BL и 5BS (Alfares et al., 2009).

\section{ЗАКЛЮЧЕНИЕ}

Ген эмбриональной летальности, обнаруженный в наших экспериментах, не может быть отнесен к генам межродовой изоляции пшеницы и ржи по очевидной причине. Несовместимые аллели этого гена найдены только у нескольких линий ржи из сотни изученных в скрещиваниях с пшеницей. Таким образом, несовместимая аллель этого гена является редкой, она не фиксирована в генотипе культурной ржи и может быть отнесена к грузу спонтанной мутационной изменчивости, свойственной ржи как объекту с перекрестным оплодотворением. Однако гибель зародышей является причиной репродуктивной изоляции в скрещиваниях многих видов и, как правило, не изучена генетически. Можно предположить, что сходство в проявлении эмбриональной летальности основано на сходстве молекулярных механизмов, ведущих к гибели зародышей и выполняющих роль межвидовых барьеров у других объектов. Возможная синтения в локализации генов Eml- $1 R$ и Eml- $1 A$ в геноме ржи и геноме А мягкой пшеницы открывает перспективы для поиска гена-кандидата не только в установленных участках хромосом 6R и 6А, но и в синтенных фрагментах хромосом у разных видов пшеницы и родственных злаков. На основе секвенирования можно сравнить последовательности совместимых и несовместимых аллелей гена $E m l-1 R$ ржи с последовательностями гомеоаллелей других злаков и сопоставить их с проявлением эмбриональной летальности, описанной в ряде межвидовых скрещиваний. Полученный в наших исследованиях генетический материал и данные о хромосомной локализации комплементарных генов пшеницы и ржи открывают перспективы подобного исследования.

Работа поддержана программой фундаментальных исследований президиума РАН «Живая природа: современное состояние и проблемы развития».

\section{ЛИТЕРАТУРА}

1. Войлоков А.В. (2008) Генетическое картирование у ржи Secale cereale L. Автореф. дис... докт. биол. наук. СПб. 
2. Войлоков А. В., Тихенко Н.Д. (2009) Генетика постзиготической изоляции у растений. Генетика. T. 45 (6): С. 729-744.

3. ГОСТ 12039-82 (2011). Межгосударственный стандарт. Семена сельскохозяйственных культур. Методы определения жизнеспособности. Москва: Стандартинформ.

4. Ригин Б. В., Орлова И. Н. (1977) Пшенично-ржаные гибриды. Ленинград: Колос.

5. Тихенко Н.Д. (2011) Генетика пшенично-ржаных гибридов и первичных октоплоидных тритикале Автореф. дис... докт. биол. наук. СПб.

6. Тихенко Н.Д., Цветкова Н. В., Войлоков А. В. (2005) Генетический контроль эмбриональной летальности при скрещивании мягкой пшеницы с рожью. Генетика. Т. 41 (8): C. 1075-1083.

7. Alfares W., Bouguennec A., Balfourier F. et al. (2009) Fine mapping and markers development for the crossability gene SKr on chromosome 5BS of hexaploid wheat (Triticum aestivum L.) Genetics. V. 183: P. 469-481.

8. Balatero C. H., Darvey N. L. (1993) Influence of selected wheat and rye genotypes on the direct synthesis of hexaploid triticale. Euphytica. V. 66: P. 179-185.

9. Deng-Cai L., Chi Y., Jun-Liang Y. et al. (1999) The chromosomal locations of high crossability genes in tetraploid wheat Triticum turgidum L. cv. Ailanmai native to Sichuan, China. Euphytica. V. 108: P. 79-82.

10. Devos K.M., Atkinson M.D., Chinoy C.N. et al. (1993) Chromosomal rearrangements in the rye genome relative to that of wheat. Theor. Appl. Genet. V. 85: P. 673-680.

11. Dobzhansky T. (1937) Genetics and the Origin of Species. N. Y.: Columbia Univ. Press.

12. Halloran G. M. (1981) Tetraploid wheat crossability with rye (Secale). Genetica. V. 55: P. 191-194.

13. Ganal M.W., Röder M.S. (2007) Microsatellite and SNP markers in wheat breeding. In Genomics Assisted Crop Improvement. V. 2: Genomics Applications in Crops, p. 1-24.

14. Khlestkina E.K., Than M.H.M, Pestsova E. G. et al. (2004) Mapping of 99 new microsatellite-derived loci in rye (Secale cereale L.) including 39 expressed sequence tags. Theor. Appl. Genet. V. 109: P. 725-732.

15. Kosellek C., Pillen K., Nelson J. C. et al. (2013) Inheritance of field resistance to Septoria tritici blotch in the wheat doubled-haploid population Solitär x Mazurka. Euphytica. V. 194: P. 161-176.

16. Lange W., Wojciechowska B. (1976) The crossing of common wheat (Triticum aestivum L.) with cultivated rye (Secale cereale L.). I. Crossability, pollen grain germination and pollen tube growth. Euphytica. V. 25: P. 609-620.

17. Lein A. (1943) The genetical basis of the crossability between wheat and rye. Z. Indukt. Abstamm. Vererbungsl. V. 81: P. 28-59.
18. Marais G. F., Pienaar R. de V. (1977) Hybridisation between wheat and rye. II. Variations in the germinability of the hybrid kernels with special reference to the effect of the D-genome. Agroplantae. V. 9: P. 143-148.

19. Martis M.M., Zhou R., Haseneyer G. et al. (2013) Reticulate evolution of the rye genome. The Plant Cell. V. 25: P. 3685-3698.

20. Muller H.J. (1942) Isolating mechanisms, evolution and temperature. Biol. Symp. V. 6: P. $71-125$.

21. Orr H.A. (1996) Dobzhansky, Bateson and the genetics of speciation. Genetics. V. 144: P. 1331-1335.

22. Pilch J. (2001) Crossability effects of spring wheat (Triticum durum Desf.) with rye (Secale cereale L.) genotypes. Plant breeding and seed science. V. 45 (2): P. 33-43.

23. Rieseberg L.H., Blackman B.K. (2010) Speciation genes in plants. Annals of Botany. V. 106: P. 439-455.

24. Riley R., Chapman V. (1967) The inheritance in wheat of crossability with rye. Genet. Res. V. 9: P. 259-267.

25. Scoles G.J. (1983) The effect of rye genotype on wheat - rye crossability and on the development of $\mathrm{F}_{1}$ seed. Can. J. Genet. Cytol. V. 25: P.668-670.

26. Sitch L.A., Snape J. W., Firman S.J. (1985) Intrachromosomal mapping of crossability genes in wheat (Triticum aestivum). Theor. Appl. Genet. V. 70: P. 309-314.

27. Thomas J.B., Kaltsikes P.J., Anderson G. (1980) Relation between whet-rye crossability and seed set of common whet after pollination with other species in the Hordeae. Euphytica. V. 30: P. 121-127.

28. Tikhenko N., N. Tsvetkova, S. Priyatkina et al. (2011) Gene mutations in rye causing embryo lethality in hybrids with wheat - allelism test and chromosomal localization. Biologia Plantarum. V. 1, 55 (3): P. 448-452.

29. Tikhenko N., Tsvetkova N., Voylokov A. (2010) Embryo lethality in wheat $\mathrm{x}$ rye hybrids - mode of inheritance and the identification of a complementary gene in wheat. Euphytica. V. 176: P. 191-198.

30. Voylokov A. V., Tikhenko N.D. (2002) Triticale as a model for study of genome interaction and genome evolution in allopolyploid plants. Proc. 5th Intern. Triticale Symp. Radzikow, 30 June-5 July 2002. V. 1. P. 63-69

31. Zheng Y.L, Luo M. C., Yen C., Yang J. L. (1992) Chromosome location of a new crossability gene in common wheat. Wheat Inf. Serv. V. 75: P. 36-40.

\section{IDENTIFICATION OF COMPLEMENTARY GENES OF HYBRID LETHALITY IN CROSSES OF BREAD WHEAT AND RYE. RESULTS AND PERSPECTIVES}

Tikhenko N.D., Tsvetkova N.V., Lyholay A.N., Voylokov A. V.

SUMMARY: Numerous genes were found in crop plants, leading to death or sterility of distant hybrids. However, the evolutionary role of concrete genes in the reproductive isolation of the species remains un- 
clear. The article summarizes the own data for identification of hybrid lethality genes that were detected in wheat -rye crosses. Seeds with the dead, undifferentiated embryo and normal endosperm were found in crosses of bread wheat with four out of a hundred studied inbred lines of rye. It is shown that the hybrid lethality is a consequence of the negative complementary interaction of genes of wheat and rye. Rye gene Eml- $1 R$ is represented by two alleles - dominant incompatible and recessive compatible. It was mapped on chromosome $6 \mathrm{R}$ relative microsatellite and isozyme loci. Complementary wheat gene $\mathrm{Eml-1A}$ is located on chromosome $6 \mathrm{~A}$. Location of interacting genes on syntenic fragments of chromosomes 6R and 6A may indicate gomeology of hybrid lethality genes in wheat and rye. However, embryonic lethality observed in individual wheat-rye hybrids, cannot be attributed to the evolutionary developed intergeneric incompatibility, like a well-studied prezygotic incompatibility of wheat and related genera.

KEY WORDS: complementary genes of hybrid lethality; wheat-rye hybrids; rye inbred lines; postzygotic reproductive isolation; gene mapping.

\section{REFERENCES (TRANSLITERATED)}

1. Voylokov A. V. (2008) Geneticheskoe kartirovanie $\mathrm{u}$ rzhi Secale cereale L. [Genetic mapping at a rye of Secale cereale L.] Abstract of the thesis... Dr. Sci. Biol. SPb.

2. Voylokov A. V., Tikhenko N. D. (2009) Genetika postzigoticheskoj izolyatsii u rastenij [Genetics of postzygotic reproductive isolation in plants]. Russian Journal of Genetics. T. 45 (6): P. 637-650.

3. GOST 12039-82 (2011). Interstate standard. Agricultural seeds. Methods for determination of viability. Moscow: Standartinform.

4. Rigin B.V., Orlova I. N. (1977) Pshenichno-rzhanye gibridy [Wheat and rye hybrids]. Leningrad: Kolos.

5. Tikhenko N. D. (2011) Genetika pshenichno-rzhanykh gibridov i pervichnykh oktoploidnykh tritikale [Genetics of wheat and rye hybrids and primary oktoploid triticale]. Abstract of the thesis... Dr. Sci. Biol. SPb.

6. Tikhenko N. D., Tsvetkova N. V., Voylokov A. V. (2005) Geneticheskij kontrol' ehmbrional'noj letal'nosti pri skreshhivanii myagkoj pshenitsy s rozh'yu [Genetic control of embryo lethality in crosses between common wheat and rye]. Russian Journal of Genetics. T. 41 (8): P. 877-884.

7. Alfares W., Bouguennec A., Balfourier F. et al. (2009) Fine mapping and markers development for the crossability gene $S K r$ on chromosome 5BS of hexaploid wheat (Triticum aestivum L.) Genetics. V. 183: P. 469-481.

8. Balatero C. H., Darvey N. L. (1993) Influence of selected wheat and rye genotypes on the direct synthesis of hexaploid triticale. Euphytica. V. 66: P. 179-185.

9. Deng-Cai L., Chi Y., Jun-Liang Y. et al. (1999) The chromosomal locations of high crossability genes in tetraploid wheat Triticum turgidum L. cv. Ailanmai native to Sichuan, China. Euphytica. V. 108: P. 79-82.
10. Devos K.M., Atkinson M.D., Chinoy C.N. et al. (1993) Chromosomal rearrangements in the rye genome relative to that of wheat. Theor. Appl. Genet. V. 85: P. 673-680.

11. Dobzhansky T. (1937) Genetics and the Origin of Species. N. Y.: Columbia Univ. Press.

12. Halloran G. M. (1981) Tetraploid wheat crossability with rye (Secale). Genetica. V. 55: P. 191-194.

13. Ganal M.W., Röder M.S. (2007) Microsatellite and SNP markers in wheat breeding. In Genomics Assisted Crop Improvement. V. 2: Genomics Applications in Crops, p. 1-24.

14. Khlestkina E. K., Than M.H.M., Pestsova E. G. et al. (2004) Mapping of 99 new microsatellite-derived loci in rye (Secale cereale L.) including 39 expressed sequence tags. Theor. Appl. Genet. V. 109: P. 725-732.

15. Kosellek C., Pillen K., Nelson J. C. et al. (2013) Inheritance of field resistance to Septoria tritici blotch in the wheat doubled-haploid population Solitär x Mazurka. Euphytica. V. 194: P. 161-176.

16. Lange W., Wojciechowska B. (1976) The crossing of common wheat (Triticum aestivum L.) with cultivated rye (Secale cereale L.). I. Crossability, pollen grain germination and pollen tube growth. Euphytica. V. 25: P. 609-620.

17. Lein A. (1943) The genetical basis of the crossability between wheat and rye. Z. Indukt. Abstamm. Vererbungsl. V. 81: P. 28-59.

18. Marais G. F., Pienaar R. de V. (1977) Hybridisation between wheat and rye. II. Variations in the germinability of the hybrid kernels with special reference to the effect of the D-genome. Agroplantae. V. 9: P. 143-148.

19. Martis M.M., Zhou R., Haseneyer G. et al. (2013) Reticulate evolution of the rye genome. The Plant Cell. V. 25: P. 3685-3698.

20. Muller H.J. (1942) Isolating mechanisms, evolution and temperature. Biol. Symp. V. 6: P. 71-125.

21. Orr H.A. (1996) Dobzhansky, Bateson and the genetics of speciation. Genetics. V. 144: P. 1331-1335.

22. Pilch J. (2001) Crossability effects of spring wheat (Triticum durum Desf.) with rye (Secale cereale L.) genotypes. Plant breeding and seed science. V. 45 (2): P. 33-43.

23. Rieseberg L.H., Blackman B.K. (2010) Speciation genes in plants. Annals of Botany. V. 106: P. 439-455.

24. Riley R., Chapman V. (1967) The inheritance in wheat of crossability with rye. Genet. Res. V. 9: P. 259-267.

25. Scoles G.J. (1983) The effect of rye genotype on wheat - rye crossability and on the development of $\mathrm{F}_{1}$ seed. Can. J. Genet. Cytol. V. 25: P. 668-670.

26. Sitch L.A., Snape J.W., Firman S. J. (1985) Intrachromosomal mapping of crossability genes in wheat (Triticum aestivum). Theor. Appl. Genet. V. 70: P. 309-314.

27. Thomas J. B., Kaltsikes P. J., Anderson G. (1980) Relation between whet-rye crossability and seed set of 
common whet after pollination with other species in the Hordeae. Euphytica. V. 30: P. 121-127.

28. Tikhenko N., N. Tsvetkova, S. Priyatkina et al. (2011) Gene mutations in rye causing embryo lethality in hybrids with wheat - allelism test and chromosomal localization. Biologia Plantarum. V 1, 55(3): P. 448-452.

29. Tikhenko N., Tsvetkova N., Voylokov A. (2010) Embryo lethality in wheat $\mathrm{x}$ rye hybrids - mode of inheri- tance and the identification of a complementary gene in wheat. Euphytica. V. 176: P. 191-198.

30. Voylokov A. V., Tikhenko N.D. (2002) Triticale as a model for study of genome interaction and genome evolution in allopolyploid plants. Proc. 5th Intern. Triticale Symp. Radzikow, 30 June-5 July 2002. V. 1. P. 63-69

31. Zheng Y. L., Luo M. C., Yen C., Yang J. L. (1992) Chromosome location of a new crossability gene in common wheat. Wheat Inf. Serv. V. 75: P. 36-40.
Тихенко Наталья Дмитриевна - старший научный сотрудник, лаборатория генетики и биотехнологии растений. Санкт-Петербургский филиал Учреждения Российской академии наук Института общей генетики им. Н. И. Вавилова РАН. 199034, Санкт- Петербург, Университетская наб., д. 5. E-mail: tikhenko@mail.ru.

Цветкова Наталья Владимировна - научный сотрудник, кафедра генетики и биотехнологии. ФГБОУ ВПО «Санкт-Петербургский государственный университет». 199034, Санкт- Петербург, Университетская наб., д. 7/9. E-mail: ntsvetkova@mai.ru.

Лыхолай Анна Николаевна - младший научный сотрудник, кафедра генетики и биотехнологии. ФГБОУ ВПО «Санкт-Петербургский государственный университет». 199034, Санкт- Петербург, Университетская наб., д. 7/9. E-mail: lankira@mail.ru.

Войлоков Анатолий Васильевич - заведующий лабораторией, лаборатория генетики и биотехнологии растений. Санкт-Петербургский филиал Учреждения Российской академии наук Института общей генетики им. Н. И. Вавилова РАН. 199034, Санкт- Петербург, Университетская наб., д. 5. E-mail: av_voylokov@mail.ru.
Tikhenko Natalia Dmitrievna - senior researcher, Dr. Biol. Sci., Laboratory of Genetics and Plant Biotechnology. St Petersburg Branch Russian Academy of Sciences, Vavilov Institute of General Genetics. 199034, Saint Petersburg, Universitetskaya nab., 5, Russia. E-mail: tikhenko@mail.ru.

Tsvetkova Natalia Vladimirovna - research scientist, PhD, Department of Genetics and Biotechnology. Saint-Petersburg State University. 199034, Saint Petersburg, Universitetskaya nab., 7/9, Russia. E-mail: ntsvetkova@mai.ru.

Lyholay Anna Nikolaevna - Junior Researcher, Department of Genetics and Biotechnology. Saint-Petersburg State University. 199034, Saint Petersburg, Universitetskaya nab., 7/9, Russia.

E-mail: lankira@mail.ru.

Voylokov Anatoly Vasilievich - Head of the Laboratory, Dr.Biol.Sci. Laboratory of Genetics and Plant Biotechnology. St Petersburg Branch Russian Academy of Sciences, Vavilov Institute of General Genetics. 199034, Saint Petersburg, Universitetskaya nab., 5, Russia.

E-mail: av_voylokov@mail.ru. 